\title{
Widespread basal cytochrome P450 expression in extrahepatic bovine tissues and isolated cells
}

\author{
M. J. Kuhn, (1) A. K. Putman, (1) and L. M. Sordillo* (1) \\ Department of Large Animal Clinical Sciences, College of Veterinary Medicine, Michigan State University, East Lansing 48824
}

\begin{abstract}
Periparturient cattle face increased risk of both metabolic and infectious diseases. Factors contributing to this predisposition include oxidized polyunsaturated fatty acids, also known as oxylipids, whose production is altered during the periparturient period and in diseased cattle. Alterations in the production of oxylipids derived from cytochrome P450 (CYP450) enzymes are over-represented during times of increased disease risk and clinical disease, such as mastitis. Many of these same CYP450 enzymes additionally regulate metabolism of fat-soluble vitamins, such as A, D, and E. These vitamins are essential to maintaining immune health, yet circulating concentrations are diminished near calving. Despite this, a relatively small amount of research has focused on the roles of CYP450 enzymes outside of the liver. The aim of this paper is to describe the relative gene expression of 11 CYP450 in bovine tissues and common in vitro bovine cell models. Eight tissue samples were collected from 3 healthy dairy cows after euthanasia. In vitro samples included primary bovine aortic and mammary endothelial cells and immortalized bovine kidney and mammary epithelial cells. Quantitative real-time-PCR was carried out to assess basal transcript expression of CYP450 enzymes. Surprisingly, CYP450 mRNA was widely expressed in all tissue samples, with predominance in the liver. In vitro CYP450 expression was less robust, with several cell types lacking expression of specific CYP450 enzymes altogether. Overall, cell culture models did not reflect expression of tissue CYP450. However, when CYP450 were organized by activity, certain cell types consistently expressed specific functional groups. These data reveal the widespread expression of CYP450 in individual organs of healthy dairy cows. Widespread expression helps to explain previous evidence of significant changes in CYP450-mediated oxylipid production and fat-soluble vitamin metabolism in organ microenvi-
\end{abstract}

Received June 5, 2019.

Accepted September 13, 2019.

*Corresponding author: sordillo@msu.edu ronments during periods of oxidative stress or disease. As such, these data provide a foundation for targeted functional experiments aimed at understanding the activities of specific CYP450 and associated therapeutic potential during times of increased disease risk.

Key words: cytochrome p450, dairy cow, oxylipid, vitamin $\mathrm{D}$

\section{INTRODUCTION}

During the periparturient period, inflammation in dairy cattle becomes dysregulated, causing impaired immune health. Dysregulated inflammation predisposes cattle to disease and excessive inflammatory tissue damage, resulting in reduced productivity (Sordillo and Raphael, 2013). Many factors contribute to the dysregulation of inflammation during the periparturient period, including the altered generation of oxidized PUFA inflammatory mediators, collectively termed oxylipids, and an inadequate amount of fat-soluble vitamins necessary for abrogating oxidative stress (Sordillo, 2016).

Oxylipids are derived non-enzymatically from exposure to reactive oxygen species and enzymatically through cyclooxygenase (COX), lipoxygenase (LOX), and cytochrome P450 (CYP450)-mediated pathways (Gabbs et al., 2015; Sordillo, 2018). Despite the historical focus placed on the COX and LOX pathways, recent work among cattle has suggested that the CYP450 pathway has a significant role in influencing health and disease. In studies profiling oxylipids in periparturient cows compared with those in other lactation stages, and cows with coliform mastitis compared with healthy controls, changes in the production of CYP450-derived oxylipids outnumbered those from either COX or LOX pathways in plasma and milk (Mavangira et al., 2015; Kuhn et al., 2017). Surprisingly, the differences noted in milk outnumbered those found in plasma, suggesting substantial local regulation of CYP450-derived oxylipids in the mammary gland.

Despite previous work showing significant production of CYP450-derived oxylipids in the mammary gland, little information is available regarding extrahepatic expression of CYP450 enzymes that may offer insight 
Table 1. Proprietary TaqMan primer or probe reference information and gene activity

\begin{tabular}{|c|c|c|c|}
\hline Gene & NCBI reference sequence ${ }^{1}$ & TaqMan assay ID & Activity $^{2}$ \\
\hline CYP2C19 & NM_001109792.2 & Bt03268476_m1 & Epoxygenase, $\mathrm{ST} \omega \mathrm{H}$ \\
\hline СYР3А4 & NM_001099367.1 & Bt03293209_sH & Epoxygenase, ST $\omega \mathrm{H}, 25$-hydroxylase \\
\hline$C Y P 4 A 11$ & NM_001077908.1 & Bt03243984_m1 & $\mathrm{TC} \omega \mathrm{H}$ \\
\hline$C Y P_{4} F_{2}$ & NM_001035042.1 & Bt03221777_m1 & 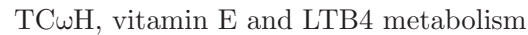 \\
\hline CYP27A1 & NM_001083413.2 & Bt03255966_m1 & 25-Hydroxylase \\
\hline CYР27B1 & NM_001192284.1 & Bt04311113_g1 & $1 \alpha$-Hydroxylase \\
\hline EPHX2 & NM_001075534.1 & Bt03241449_m1 & Epoxide hydrolase \\
\hline RPS9 & NM_001101152.2 & Bt03272017_m1 & Reference gene \\
\hline
\end{tabular}

${ }^{1}$ National Center for Biotechnology Information reference sequence found in the nucleotide database (https://www.ncbi.nlm.nih.gov/nuccore/). ${ }^{2} \mathrm{ST} \omega \mathrm{H}=$ subterminal $\omega$-hydroxylase; TC $\omega \mathrm{H}$ = terminal carbon $\omega$-hydroxylase; LTB4 = leukotriene B4.

${ }^{3}$ Information regarding the creation of custom TaqMan primer and probe sets can be found in Table 2.

into the mechanisms behind local regulation of these lipid mediators (Mavangira et al., 2015; Kuhn et al., 2017). Given the diverse activities of CYP450 enzymes (Table1), functional studies are necessary to understand the specific CYP450 enzymes contributing to oxylipid production. Establishing a transcript expression profile of CYP450 enzymes builds a foundation for such studies, given that extrahepatic expression for many CYP450 has not yet been shown.

The multiple activities of individual CYP450 and redundant activities between them create a complex network of oxylipid and vitamin regulation with multiple instances of substrate and function crossover. Understanding the unique activities of individual CYP450 and overlapping activities between them is key to understanding their roles in health and disease. For example, several CYP450 may metabolize arachidonic acid into oxylipids, 7 of which were included in this study (Figure 1A). Currently, no study in cattle has established the relative contribution of differing CYP450 to the overall oxylipid pool. Due to this, CYP450 that metabolize PUFA chosen for this study were selected based on their significant contribution to the oxylipid pool in other species, such as CYP2C19, CYP2E1, CYP3A4, CYP4A11, and CYP4F2, or previous research in cattle that has explored the activity of a specific CYP450, such as CYP1A1 or CYP2J2 (Lasker et al., 2000; Yang et al., 2001; Fer et al., 2008; Zhang et al., 2018).

A subset of these PUFA-metabolizing CYP450, the CYP450 family 4 (CYP4) class, including CYP4A11 and $\mathrm{CYP} 4 \mathrm{~F} 2$, have predominantly terminal carbon $\omega$-hydroxylase activity $(\mathbf{T C} \boldsymbol{\omega} \mathbf{H})$, producing the highly pro-inflammatory 20-hydroxyeicosatetraenoic acid (20HETE) as their primary product (Powell et al., 1998). In contrast, CYP1A1, CYP2C19, CYP2E1, CYP2J2, and CYP3A4 generally act as epoxygenases, creating 4 isomers of epoxyeicosatrienoic acids (EET) as a primary product. These EET are further metabolized by the non-CYP450 enzyme soluble epoxide hydrolase (EPHX2) to secondary and presumably less antiinflammatory oxylipid metabolites. As such, EPHX2 is an enzymatic step that has been targeted in other veterinary species for therapeutic intervention for the reduction of pain due to inflammation (Bylund et al., 1998; Guedes et al., 2017). Secondarily, and to a lesser extent, these latter 5 epoxygenases metabolize arachidonic acid by hydroxylating carbons 16-19, thus acting as subterminal $\omega$-hydroxylases $(\mathbf{S T} \boldsymbol{\omega} \mathbf{H})$, a class of oxylipids whose activities are only beginning to be understood in veterinary research.

Whereas oxylipids are direct mediators of inflammation, fat-soluble vitamins $\mathrm{A}, \mathrm{D}$, and $\mathrm{E}$ act upon inflammation both directly, through regulation of inflammatory signaling, and indirectly, as antioxidants curtailing oxidative stress (Sordillo, 2016). Although the mechanisms by which fat-soluble vitamins can influence inflammation differ from oxylipids, their regulation shares many of the same CYP450 enzymes that regulate oxylipid production. For example, epoxygenases CYP2J2 and CYP3A4 also act as a 25-hydroxylase of vitamin D, along with CYP27A1, to form 25-hydroxyvitamin $\mathrm{D}_{3}\left[\mathbf{2 5}-(\mathbf{O H}) \mathrm{D}_{3}\right.$; Figure 1B]. Although several CYP450 have been identified as 25-hydroxylases in other species, no studies have conclusively identified the relative contribution of each of these enzymes to the overall production of $25-(\mathrm{OH}) \mathrm{D}_{3}$ in cattle. It has been shown, however, that polymorphisms in CYP2J2 and $C Y P 27 A 1$ lead to reduced serum $25-(\mathrm{OH}) \mathrm{D}_{3}$ and ultimately are associated with incidence of milk fever (Casas et al., 2013; Pacheco et al., 2018). Although these studies do not provide direct evidence of activ- 
A)

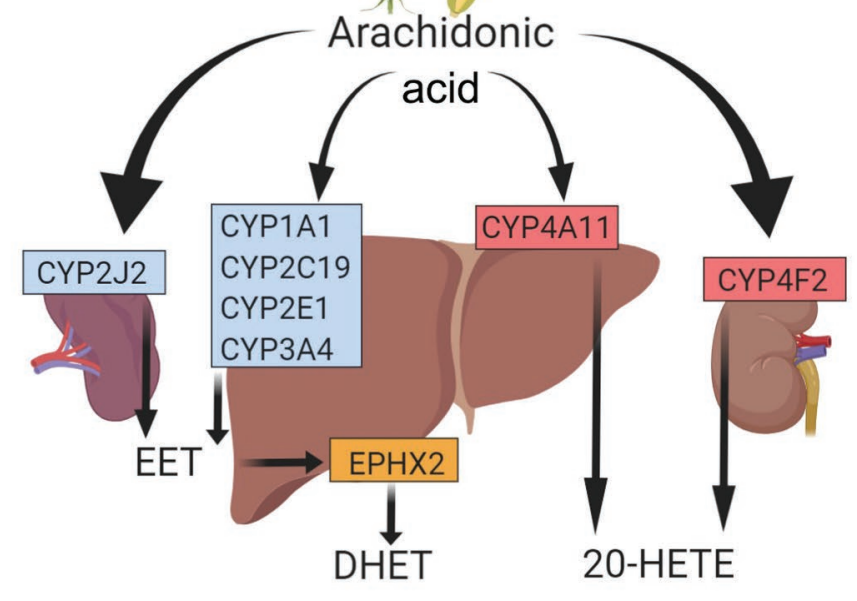

B)

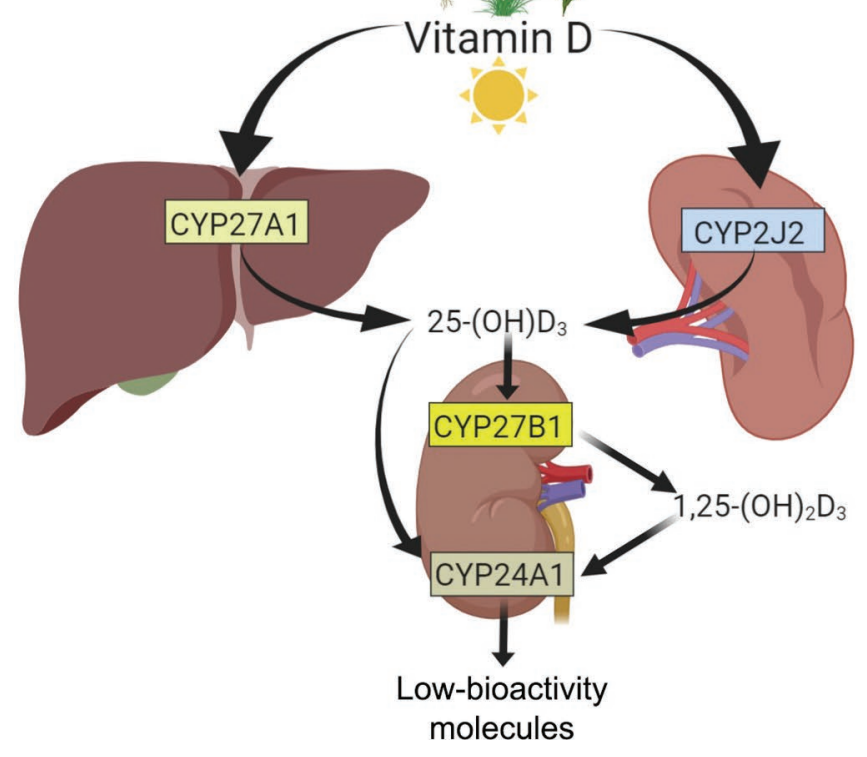

C)
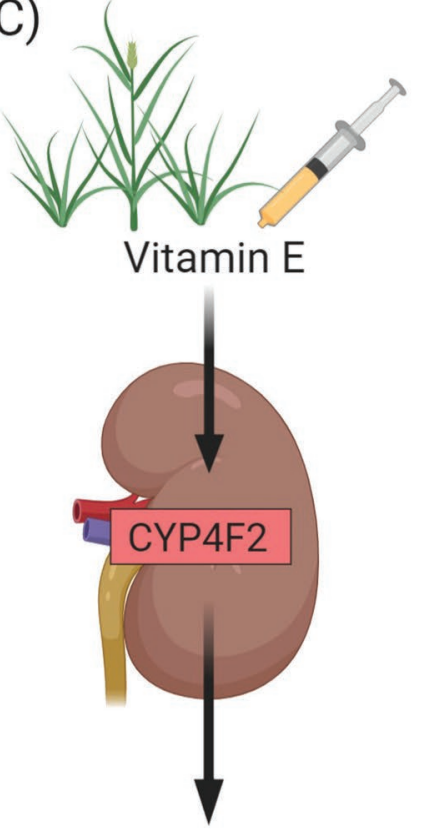

13'-carboxychromanol

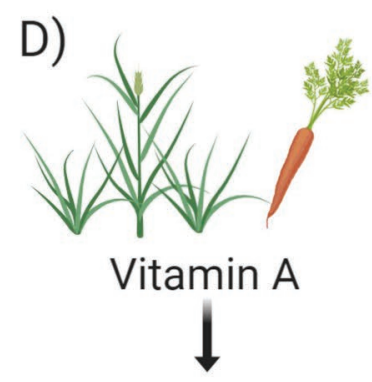

All-trans RA, 9-cis RA, 13-cis RA

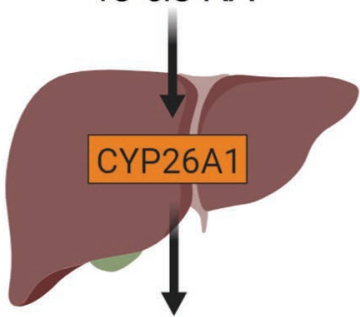

Low-bioactivity molecules

Figure 1. Cytochrome P450 enzymes are placed upon their organ of highest mRNA expression as follows: (A) from left to right, spleen, liver, kidney; (B) clockwise from upper left, liver, spleen, kidney; (C) kidney; (D) liver. (A) Several cytochrome P450 enzymes are capable of metabolizing PUFA; shown here are pathways of arachidonic acid metabolism. Cytochrome P450 enzymes (backed by blue and on the left) act as epoxygenases producing epoxyeicosatrienoic acids (EET) that can be further metabolized by the enzyme EPHX2 to dihydroxyeicosatrienoic acids (DHET). Cytochrome P450 enzymes (backed in red, on the right) have predominantly terminal carbon w-hydroxylase activity, producing 20-hydroxyeicosatetraenoic acid (20-HETE). (B) Cytochrome P450 enzymes involved in the activation and inactivation of vitamin D. Vitamin $\mathrm{D}$ is obtained from either exposure of the skin to UV light or directly from the diet, as either vitamin $\mathrm{D}_{2}$ or vitamin $\mathrm{D}_{3}$. Shown is the cascade for vitamin $\mathrm{D}_{3}$ as the initial compound is metabolized to 25-hydroxyvitamin $\mathrm{D}_{3}\left[25-(\mathrm{OH}) \mathrm{D}_{3}\right]$ by at least 2 cytochrome p450 enzymes in cattle, CYP27A1 and CYP2J2. Then, $25-(\mathrm{OH}) \mathrm{D}_{3}$ is metabolized by the $1 \alpha$-hydroxylase CYP27B1 to produce active vitamin D, 1,25 -dihydroxyvitamin $\mathrm{D}_{3}\left[1,25-(\mathrm{OH})_{2} \mathrm{D}_{3}\right]$. Ultimately, both $25-(\mathrm{OH}) \mathrm{D}_{3}$ and $1,25-(\mathrm{OH})_{2} \mathrm{D}_{3}$ are inactivated by CYP24A1 to molecules of low bioactivity such as 24,25-dihydroxycholecalciferol or calcitroic acid. (C) All 8 analogs of vitamin E are hydroxylated by CYP4F2 to form analog-specific forms of 13'-carboxychromanol. 13'-carboxychromanol is readily metabolized by other means to water-soluble metabolites, some of which have significant bioactivity. (D) Vitamin A is a group of compounds, including carotenoids and retinyl esters, ultimately metabolized to forms of retinoic acids, including all-trans retinoic acid (RA), 9-cis RA, and 13-cis RA. Such RA are metabolized by cytochrome P450 family 26 enzymes, specifically CYP26A1 evaluated in this study, to metabolites with little bioactivity. Figure created with BioRender.com. 
ity or discount the potential activity of other CYP450 25-hydroxylases, they nonetheless provide evidence of specific CYP450 that have clinical effects on the health of cattle. Metabolism of vitamin D continues with the activation of $25-(\mathrm{OH}) \mathrm{D}_{3}$ to 1,25-dihydroxyvitamin $\mathrm{D}_{3}$ $\left[\mathbf{1 , 2 5}-(\mathrm{OH})_{2} \mathrm{D}_{3}\right]$, the active form of vitamin $\mathrm{D}$, solely by CYP27B1. Last in this cascade, CYP24A1 alone is responsible for the ultimate degradation of $25-(\mathrm{OH}) \mathrm{D}_{3}$ and $1,25-(\mathrm{OH})_{2} \mathrm{D}_{3}$ to inactive compounds (Christakos et al., 2016).

Vitamins A and E also can be degraded by CYP450. In addition to its $\mathrm{TC} \omega \mathrm{H}$ activity, $\mathrm{CYP} 4 \mathrm{~F} 2$ is the single CYP450 responsible for the degradation of analogs of vitamin E to their inactive forms (Figure 1C; Sontag and Parker, 2002). Further, the cytochrome P450 family 26 (CYP26) class of enzymes degrades active forms of vitamin A to less bioactive metabolites (Figure 1D; Ross and Zolfaghari, 2011). As with CYP450-derived oxylipids, the regulation of these vitamins is disturbed during times of greatest need (LeBlanc et al., 2004; Holcombe et al., 2018). Regulation of vitamin metabolism is another essential aspect of understanding how CYP450 enzymes affect cow health and disease.

Modeling the function of CYP450 enzymes will require an understanding of their transcriptional expression in cell culture systems that are relevant to bovine health and production. Bovine mammary alveolar epithelial cells (MAC-T) and Madin-Darby bovine kidney cells (MDBK) are commonly sought for their immortalized nature, providing reproducible results through many passages (Madin and Darby, 1958; Huynh et al., 1991). On the other hand, primary cells, such as bovine aortic endothelial cells (BAEC) and bovine mammary endothelial cells (BMEC), are valued for their phenotypic similarities to in vivo counterparts (Yang et al., 2001; Ryman et al., 2016).

Although CYP450 have the capacity to significantly affect inflammation by regulating vitamin metabolism and contributing to the oxylipid pool, their relative expression in cattle and potential for study using in vitro models is largely unknown. The aim of this study was to describe the relative basal transcript expression of CYP450 enzymes relevant to the regulation of inflammation in healthy cattle. Additionally, with the need for in vitro models for functional studies of CYP450 enzymes, expression of these CYP450 was evaluated in both primary and immortalized cell lines of endothelial and epithelial cells, respectively. Many studies have evaluated a single CYP450 or a small subset of such enzymes; however, none have explored such a wide range of enzymes among the many tissues of cattle nor presented data in a manner that allows for comparison between CYP450, as described herein. Furthermore, no studies as of yet have evaluated relative expression of CYP450 between commonly used in vitro bovine models. This report expands our current understanding of CYP450 expression in cattle, showing novel tissue expression of several enzymes and offering a foundation for future functional assays to build from.

\section{MATERIALS AND METHODS}

\section{Chemicals and Reagents}

QIAzol lysis regent and RLT buffer were purchased from Qiagen Sciences (Germantown, MD). Chloroform was purchased from Thermo Fisher Scientific (Fair Lawn, NJ) and Dulbecco's modified Eagle's medium was obtained from Gibco (Thermo Fisher Scientific). Collagenase and Hanks' balanced salt solution (HBSS) were purchased from Sigma-Aldrich (St. Louis, MO). Ham's F-12K medium was purchased from Irvine Scientific (Santa Ana, CA).

\section{Animals and Tissue Sampling}

Three multiparous Holstein cows were culled from the Michigan State University Dairy Teaching and Research Center (East Lansing) for non-disease-related reasons. Parity ranged from lactation 3 to 7 , with all cows between 74 and 163 DIM. Production in the previous lactation ranged from 8,095 to $13,641 \mathrm{~kg}$ of milk on a 305-d milking average. Two cows were open, and 1 was pregnant at the time of culling. The cows were milked twice daily, kept in a freestall barn, offered water ad libitum, and fed a TMR twice daily.

Cows were euthanized by captive bolt and exsanguination, and tissues were collected within $15 \mathrm{~min}$ of euthanasia. Samples of liver, kidney, heart, skeletal muscle, spleen, mammary gland, lung, and uterus were taken aseptically by removing roughly $0.5-\mathrm{cm}$ pieces of organ tissue from areas devoid of serosal surfaces or large vasculature. Samples were placed in 2-mL Eppendorf tubes, flash frozen in liquid nitrogen, and stored at $-80^{\circ} \mathrm{C}$ for less than 3 mo before RNA extraction.

\section{Primary Cell Isolation}

Bovine mammary endothelial cells and BAEC were collected as described previously (Aherne et al., 1995). Briefly, for BAEC isolation, a 10-cm full-circumference section of descending aorta, just distal to the branch of the subclavian artery, was collected at a commercial abattoir and immediately submerged in HBSS with $0.05 \mathrm{mg} / \mathrm{mL}$ gentamicin on ice. Pudendal artery for BMEC isolation was collected by taking a $4-\mathrm{cm}$ fullcircumference sample of pudendal artery near the cut edge of the mammary gland, submerged immediately 
in HBSS with $0.05 \mathrm{mg} / \mathrm{mL}$ gentamicin, and placed on ice. Once transported to the laboratory for processing, aorta samples were cut lengthwise and laid flat in a solution of $2 \mathrm{mg} / \mathrm{mL}$ collagenase in Krebs-Ringer bicarbonate with $4 \% \mathrm{BSA}$ and allowed to incubate at $37^{\circ} \mathrm{C}$ for 10 min. Pudendal artery samples were rinsed with HBSS and clamped at one end, filled with a solution of $2 \mathrm{mg} / \mathrm{mL}$ collagenase in Krebs-Ringer bicarbonate with $4 \%$ BSA, clamped at the remaining open end, and incubated for $10 \mathrm{~min}$ at $37^{\circ} \mathrm{C}$. After each incubation, the collagenase solution was collected and the luminal sides of tissues were rinsed with HBSS, collecting the rinse solution. The rinse solution was added to collected collagenase and samples were centrifuged at $160 \times g$ for $10 \mathrm{~min}$ at $15^{\circ} \mathrm{C}$. Resulting cellular pellets were plated in T25 cell culture flasks until confluent in Ham's F12K medium containing $10 \%$ fetal bovine serum, $10 \mathrm{mM}$ HEPES buffer, $0.25 \%$ sodium bicarbonate, $2 \mathrm{mM}$ Lglutamine, $1 \% \quad 1: 1$ antibiotic:antimycotic, $100 \mu \mathrm{g} / \mathrm{mL}$ heparin, $10 \mu \mathrm{g} / \mathrm{mL}$ insulin, $5 \mu \mathrm{g} / \mathrm{mL}$ transferrin, and $40 \mathrm{ng} / \mathrm{mL}$ sodium selenite.

Cells were detached via incubation with $0.05 \%$ trypsin, diluted serially, and plated in 96-well plates. To exclude fibroblasts and other cell types, wells containing only colonies derived from a single cell were selected for propagation. Wells were selected by typical endothelial cobblestone morphology for further propagation and confirmed by von Willebrand factor staining. Cells were frozen at passage 3 and grown to passage 6 for RNA isolation, representing the earliest passage at which cells could realistically be used for assays.

\section{Cell Line Culture}

Madin-Darby bovine kidney cells were obtained from the American Type Culture Collection (Manassas, VA), and MAC-T cells were obtained from the USDA Agricultural Research Service as a line of primary mammary alveolar cells transfected with SV-40 large T-antigen for immortalization (Huynh et al., 1991). Both MDBK and MAC-T cells were cultured in Dulbecco's modified Eagle's medium $(+4.5 \mathrm{~g} / \mathrm{L}$ D-glucose) devoid of phenol red, sodium pyruvate, or L-glutamine. Added to this medium were the following: $10 \%$ fetal bovine serum, 10 $\mathrm{m} M$ HEPES buffer, $0.25 \%$ sodium bicarbonate, $2 \mathrm{mM}$ L-glutamine, $1 \%$ 1:1 antibiotic:antimycotic, $100 \mu \mathrm{g} / \mathrm{mL}$ heparin, $10 \mu \mathrm{g} / \mathrm{mL}$ insulin, $5 \mu \mathrm{g} / \mathrm{mL}$ transferrin, and $40 \mathrm{ng} / \mathrm{mL}$ sodium selenite. Cell were incubated at $5 \%$ $\mathrm{CO}_{2}$ and $37^{\circ} \mathrm{C}$.

\section{RNA Extraction}

Tissues were cut into 30 - to $40-\mathrm{mg}$ pieces with a sterile scalpel while still frozen and added to $450 \mu \mathrm{L}$ of QIAzol lysis reagent (Qiagen). Samples of muscle tissue were cut into 80-mg pieces for homogenization. A TissueRuptor II tissue homogenizer (Qiagen) was run at maximum allowable speed for 1 min for tissue homogenization. An additional $450 \mu \mathrm{L}$ of QIAzol was added to samples, which were then incubated at room temperature for 5 min. After incubation, $180 \mathrm{uL}$ of chloroform was added to each tube, and tubes were vigorously shaken for $15 \mathrm{~s}$ and incubated at room temperature for $3 \mathrm{~min}$. Samples were centrifuged at $12,000 \times g, 4^{\circ} \mathrm{C}$, for $15 \mathrm{~min}$, and the upper aqueous layer was removed and added to a new 2-mL tube for RNA extraction.

Cultured cells were grown on 100-mm cell culture treated dishes. Once confluent, dishes were washed twice with HBSS and $600 \mu \mathrm{L}$ of buffer RLT (Qiagen) was added for cell lysis. Buffer RLT was collected, added to QIAShredders nested in 2-mL Eppendorf tubes, and spun at $16,000 \times g$ for $2 \mathrm{~min}$. Flow-through was stored at $-20^{\circ} \mathrm{C}$.

Once all tissue and cell culture samples were obtained, RNA was extracted according to the Qiagen RNeasy protocol with DNase digest, using a QIAcube (Qiagen). RNA quantity and quality were quantified using a NanoDrop ND-1000 spectrophotometer (Thermo Fisher).

\section{Reverse Transcription}

For cDNA generation, RNA was diluted with nuclease-free water to standardize all samples. A master mix of $10 \times$ reverse-transcription buffer, $25 \times$ dNTP, $10 \times$ random primers, Multiscribe reverse transcriptase, RNase inhibitor, and RNase nuclease-free water from a high-capacity cDNA reverse-transcription kit with RNase inhibitor (all kit components from Applied Biosystems, Vilnius, Lithuania), was added at an equal volume to diluted RNA. Samples were placed in a PTC-200 Peltier Thermo Cycler (MJ Research, Waltham, MA), which ran as follows: stage $1,25^{\circ} \mathrm{C}$ for $10 \mathrm{~min}$; stage $2,37^{\circ} \mathrm{C}$ for $2 \mathrm{~h}$; stage $3,85^{2} \mathrm{C}$ for $5 \mathrm{~min}$; stage 4 , hold at $4^{\circ} \mathrm{C}$.

\section{Real-Time PCR}

Real-time PCR was carried out with predesigned TaqMan primers and FAM-MGB probes (Applied Biosystems, Pleasanton, CA) for those genes listed in Table 1. Two genes were created as custom TaqMan primers, listed in Table 2. All primers and probes were used in a 7500 Fast Real-time PCR system (Applied Biosystems). Genes were evaluated in triplicate with $2 \times$ TaqMan Gene Expression Master Mix (Applied Biosystems), 20× Custom TaqMan Gene Expression Assay Mix (Applied Biosystems), sample cDNA (50 
Table 2. Primer sequences for custom TaqMan primers

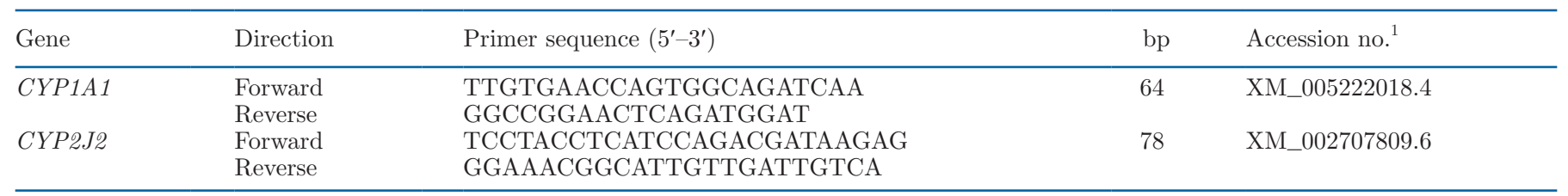

${ }^{1}$ Accession numbers from National Center for Biotechnology Information gene bank database (https://www.ncbi.nlm.nih.gov/gene).

$\mathrm{ng} /$ well for tissues, $100 \mathrm{ng} /$ well for cells), and nucleasefree water for a total of $10 \mu \mathrm{L}$ per reaction well. A $20 \times$ pre-designed TaqMan Gene Expression Assay for RPS9 was used as endogenous control (Applied Biosystems). Thermal cycling conditions for the Fast 2-step PCR system were as follows: stage $1,95^{\circ} \mathrm{C}$ for $20 \mathrm{~s}$; stage 2 , $95^{\circ} \mathrm{C}$ for $3 \mathrm{~s}$; stage $3,60^{\circ} \mathrm{C}$ for $30 \mathrm{~s}$, with 40 cycles of stages 2 and 3. Data were recorded and compiled using ExpressionSuite Software version 1.0.4 (Applied Biosystems) and analyzed using DataAssist Software version 3.01 (Applied Biosystems, Foster City, CA). Data from tissues and in vitro cell samples, having no standard cell type for comparison, are expressed as $2^{-\Delta \mathrm{CT}}$.

Efficiency (E) of PCR was calculated based on the slope of a standard curve of tissue samples, serially diluted. The slope of the standard curve was used to calculate $\mathrm{E}$, using the equation $\mathrm{E}=\left(10^{-1 / \text { slope }}-1\right)$ $\times$ 100. Calculated efficiency was $100.04 \%$ for $C Y P 1 A 1$ and $99.99 \%$ for CYP2J2, verifying acceptable efficiency for these TaqMan custom primer and probe sets.

\section{RESULTS}

\section{Tissue Expression}

Gene expression of CYP450 enzymes in tissues of major organs of dairy cattle was surprisingly widespread, with every CYP450 evaluated found to be expressed in at least 1 sample of every tissue type (Figure 2). As expected, the liver, in general, expressed all CYP450 to the highest degree, with the only exceptions being CYP2J2, CYP24A1, and CYP27B1.

Oxylipid Metabolism. The CYP450 that metabolize oxylipids from PUFA substrate in this study include CYP1A1, CYP2C19, CYP2E1, CYP2J2, CYP3A4, CYP4A11, and CYP4F2. Of the CYP450 with significant epoxygenase and $\mathrm{ST} \omega \mathrm{H}$ activity, including CYP1A1, CYP2C19, CYP2J2, CYP2E1, and CYP3A4, all were found to have greatest expression in the liver except for CYP2J2. Instead, CYP2J2 was expressed in splenic and lung tissue 6.06-fold and 1.42-fold above liver expression, respectively $\left(2^{-\triangle \Delta \mathrm{CT}}\right.$, reference gene RPS9). Additionally, CYP1A1 and CYP3A4 each had their second-greatest expression in lung tissue, whereas CYP2E1 and CYP2C19 had the lowest tissue expres- sion in the lung. Although there are inherent differences between the isolation of specific CYP450 and reverse transcriptase efficiency, samples were processed as a single batch, ensuring appropriate RNA quality, and used a single lot of reverse transcriptase to reduce these effects. Comparing CYP450, we found CYP2C19 to be expressed to a considerably greater amount in the liver than the next closest epoxygenase $\left(C Y P 2 C 192^{-\triangle \mathrm{CT}}\right.$ of 87.69, compared with 28.09 of CYP2E1 or 5.19 of CYP1A1; reference gene RPS9) and was the predominate epoxygenase in the mammary gland, heart, and uterus, in each case followed in expression by $C Y P 1 A 1$ and CYP2E1 sequentially. In the lung, CYP2C19 dominated epoxygenase expression with little comparable expression by any other epoxygenase. Interestingly, the spleen was comparatively devoid of epoxygenase expression apart from CYP2J2.

Of the 2 TCwH enzymes, CYP4A11 was most highly expressed in the liver and secondarily in the kidney, whereas CYP4F2 had a significantly greater expression in the kidney than any other tissue. Additionally, CYP 4 F2 was also the only CYP450 not reliably expressed in each tissue type, with samples of skeletal muscle, spleen, and uterus devoid of expression of this enzyme. Despite increased expression of $C Y P 4 F 2$ in the kidney compared with the liver, overall transcription of $C Y P 4 F 2$ paled in comparison to $C Y P 4 A 11$ in all tissues.

Although not a CYP450 enzyme, the EPHX2 enzyme is instrumental in secondary metabolism of CYP450-derived epoxides, such as metabolizing EET to DHET. We found that EPHX2 was expressed to the greatest amount in the liver compared with reference gene $\operatorname{RPS9}\left(2^{-\triangle \mathrm{CT}}\right.$ of 1.3$)$, and to a lesser amount in other tissues, having its second highest expression in the kidney $\left(2^{-\Delta \mathrm{CT}}\right.$ of 0.31$)$, followed by other organs, which were expressed at similar amounts $\left(2^{-\Delta \mathrm{CT}}\right.$ ranging from 0.012 to 0.12 ).

Vitamin D Metabolism. Of the 325 -hydroxylases evaluated in this study, CYP27A1 and CYP3A 4 were both expressed to the highest extent in liver tissue, whereas CYP2J2 was expressed most highly in the spleen. Between CYP450, CYP27A1 was found to be the most highly expressed 25-hydroxylase in every tissue type and had the most consistent expression profile between tissues. 
We found CYP27B1 expressed to a considerably greater amount in the kidney than in any other tissue, with the next highest expression in heart and uterine tissues. The 24-hydroxylase CYP24A1 was also relatively highly expressed in the kidney compared with all other tissues, apart from the uterus. Interestingly, 1 sample of uterine tissue was found to have expression of CYP24A1 comparable to those found in the kidney, whereas the remaining 2 uterine tissue samples had levels near that of liver.
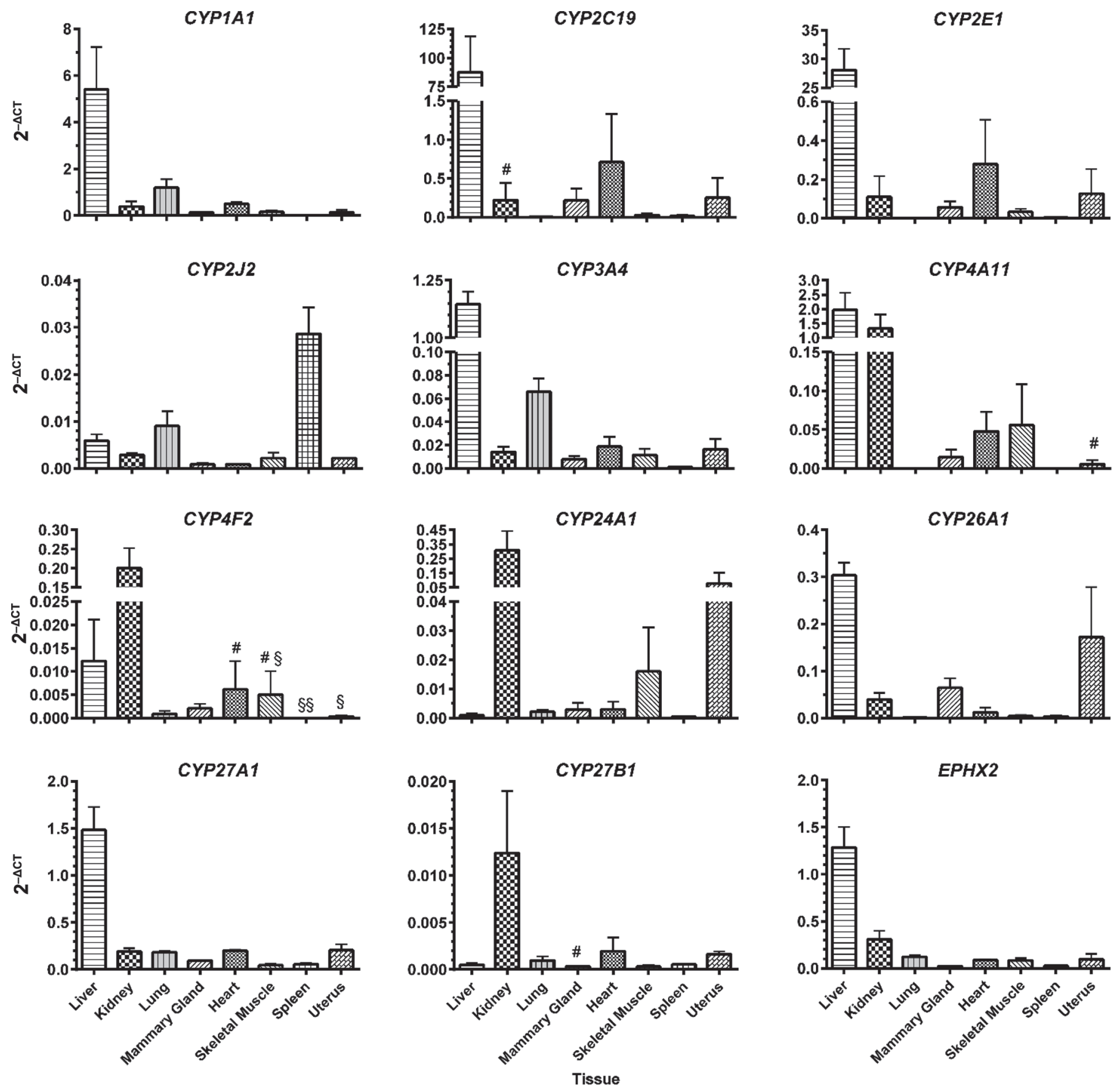

Figure 2. Relative abundance (mean $\pm \mathrm{SEM}$ ) of gene transcripts for $C Y P 1 A 1, C Y P 2 C 19, C Y P 2 E 1, C Y P 2 J 2, C Y P 3 A 4, C Y P 4 A 11, C Y P 4 F 2$, CYP24A1, CYP26A1, CYP27A1, CYP27B1, and EPHX2 found in liver, kidney, lung, mammary gland, heart, skeletal muscle, spleen, and uterine tissues from healthy, lactating dairy cows $(\mathrm{n}=3)$. §Presented value excludes sample not found during PCR cycling. \#Presented value contains samples with cycle to threshold value $>35$ cycles. §§Presented value excludes 2 samples not found during PCR cycling. Values are presented as transcript abundance $\left(2^{-\triangle \mathrm{CT}}\right)$ relative to endogenous control gene $R P S 9$. 
Vitamin A Metabolism. We found CYP26A1 to be transcribed in all tissue types, with the highest expression in the liver, followed closely by uterine tissue. Moderate expression was noted in heart, kidney, and mammary tissue, with low expression in lung, skeletal muscle, and spleen.

\section{Cell Culture Expression}

Oxylipid Metabolism. Gene expression of oxylipidproducing CYP450 in cultured bovine cells was far less robust than noted in tissues. We found that CYP2C19 and $C Y P 4 F 2$ were not reliably expressed by any cell type evaluated, $C Y P 4 A 11$ only consistently expressed in BAEC, and CYP2E1 only consistently expressed in BAEC and MAC-T (Table 3). Additionally, CYP2J2 was not expressed by a clone of the MDBK cell line. The MAC-T cell line expressed both CYP1A1 and $C Y$ 2 2J2 to considerably greater amounts, over 10-fold, compared with the next highest-expressing cell type (Figure 3). Expression of CYP3A4 varied between cell types but was nonetheless reliably expressed in each sample. We found that EPHX2 was similarly expressed among cell types but considerably lower in MDBK cells.

Vitamin D Metabolism. Of all 25-hydroxylases evaluated, CYP27A1 was expressed to the highest amount and was consistently expressed among cell types, aside from MAC-T cells, for which CYP27A1 had measurable yet low expression (Figure 3 ). The final 2 steps of vitamin D metabolism, $C Y P^{2} 7 B 1$ and $C Y$ $P 24 A 1$, were both reliably expressed in all cell types. Although both $C Y P^{2} 7 B 1$ and $C Y P^{2} 4 A 1$ had greater expression in MAC-T cells compared with either endothelial cell type, MDBK expression was converse, representing the lowest expressing cell type of $C Y P 27 B 1$ yet highest expressing cell type of CYP24A1.

Vitamin A Metabolism. In cell culture models, CYP26A1 was consistently expressed among all cell types, with greatest expression in MAC-T and lowest in MDBK cells. Compared with other CYP450, however, CYP26A1 was expressed to a comparatively lesser amount (Figure 3).

\section{DISCUSSION}

Circulating concentrations of oxylipids and fat-soluble vitamins $\mathrm{A}, \mathrm{D}$, and $\mathrm{E}$ fluctuate during the periparturient period in cattle, contributing to a state of oxidative stress and dysfunctional inflammation at this time (Sordillo, 2016, 2018). Despite influencing inflammation through differing mechanisms, these metabolites share regulation by the CYP450 enzymatic pathway. Nevertheless, before this study, little was known about
Table 3. Cell samples with cycles to threshold $(\mathrm{CT})$ values $>35$ cycles or undetected $(\mathrm{n}=3)$

\begin{tabular}{lcccc}
\hline & \multicolumn{4}{c}{ Cell type $^{1}$} \\
\cline { 2 - 5 } Gene & BAEC & BMEC & MAC-T & MDBK \\
\hline CYP2C19 & 30.05 & 37.33 & $35.54^{2}$ & $27.03^{2}$ \\
CYP2E1 & 28.86 & $35.94^{2}$ & 34.27 & $35.56^{2}$ \\
CYP4A11 & 33.62 & $29.07^{2}$ & $37.09^{2}$ & $36.99^{2}$ \\
CYP4F2 & -3 & -3 & $33.31^{2}$ & $36.95^{2}$ \\
\hline
\end{tabular}

${ }^{1} \mathrm{BAEC}=$ bovine aortic endothelial cell; $\mathrm{BMEC}=$ bovine mammary endothelial cell; MAC-T = bovine immortalized mammary epithelial cells; MDBK = Madin-Darby bovine kidney epithelial cell.

${ }^{2}$ Excludes samples with no expression.

${ }^{3}$ No expression found in any sample (100 ng of RNA).

the extrahepatic expression of specific CYP450 in dairy cattle. Surprisingly, every CYP450 evaluated herein, apart from $C Y P_{4}$ F2, was transcriptionally expressed in every tissue sampled. Although extrahepatic expression was relatively low for many CYP450, local effects of CYP450 should not be overlooked. For example, infusion of LPS into the mammary gland results in isolated activation of CYP450 involved in the regulation of vitamin D without changes in activation of CYP450 noted outside of the mammary gland (Merriman et al., 2018).

Conclusions drawn from these data are limited by the understanding that gene expression does not directly relate to activity of an enzyme. Post-transcriptional and translational modification through phosphorylation, glycosylation, and protein degradation are all known to modify the activity of CYP450 (Aguiar et al., 2005). In general, however, CYP450 activity is influenced most by substrate availability, such as the induction of $C Y P 24 A 1$ by $1,25-(\mathrm{OH})_{2} \mathrm{D}_{3}$ or CYP26A1 by vitamin $\mathrm{A}$ (Krüger et al., 2005; Merriman et al., 2017). As such, detailing mRNA expression to understand the breadth of CYP450 distribution in various organs is needed as a first step for functionality research.

Samples with cycles to threshold (CT) values of greater than 35 cycles were not included in Figure 3, as quantitative accuracy diminishes beyond this point (Lorenz, 2012). Such samples, included in Table 3, cannot be compared directly to those with reliable expression. Tissue samples included bovine liver, kidney, mammary gland parenchyma, lung, spleen, heart, skeletal muscle, and full-thickness uterus from healthy, multiparous, lactating cows.

\section{Epoxygenases}

The epoxygenases examined in this study were CYP1A1, CYP2C19, CYP2E1, CYP2J2, and CYP3A4 (Fer et al., 2008). Unlike previous reports, we found that CYP1A1 was not distributed evenly among tis- 
sues but had a preponderance in the liver similar to other CYP450 (Darwish et al., 2010). Prominent lung expression, compared with other CYP450, however, is in line with a previous report in human tissue profiling. Such lung expression may underscore the importance of STwH activity also noted from epoxygenases such as
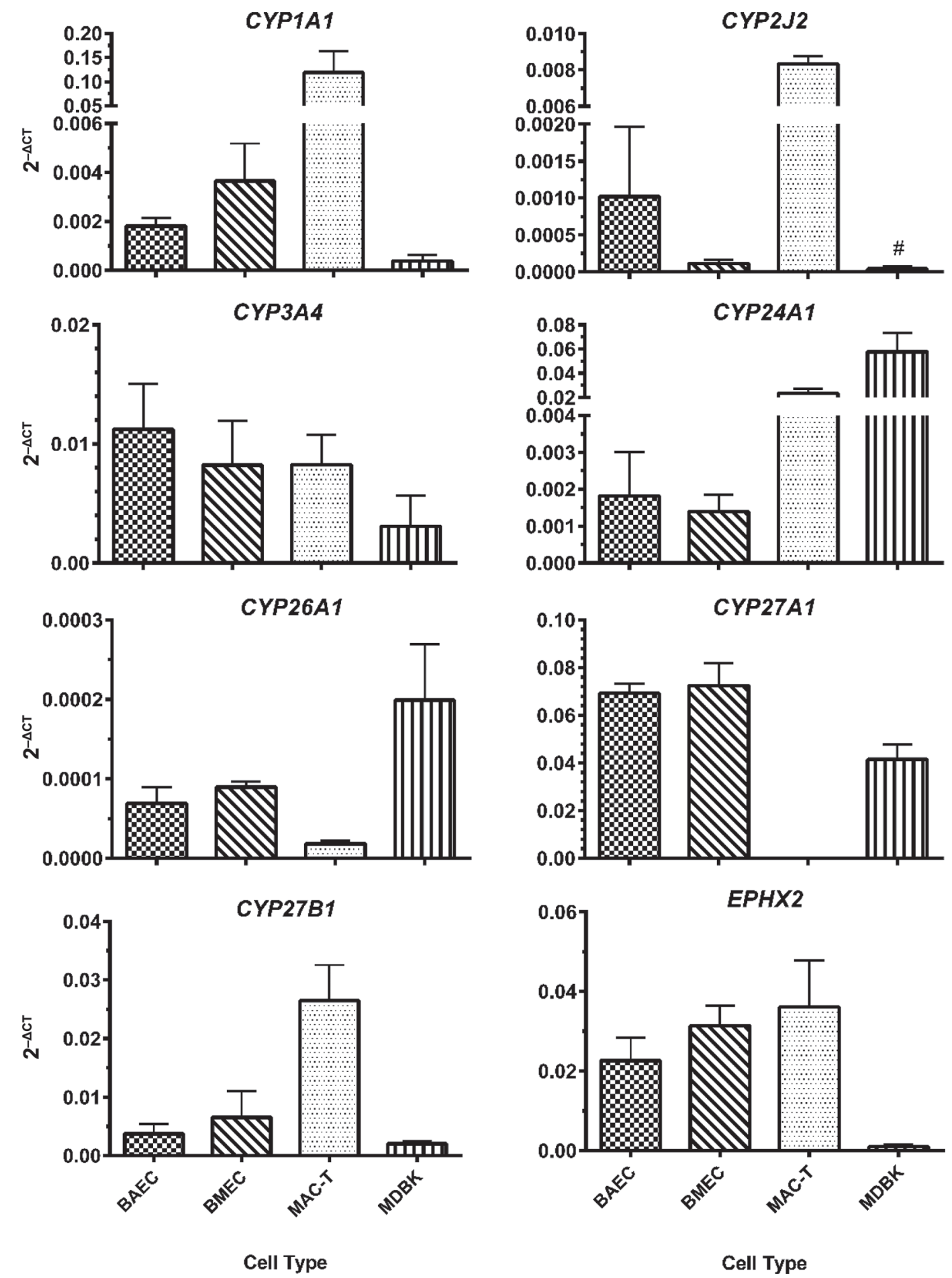

Figure 3. Relative abundance (mean $\pm \mathrm{SEM}$ ) of gene transcripts for CYP1A1, CYP2J2, CYP3A4, CYP24A1, CYP26A1, CYP27A1, CYP27B1, and EPHX2 in bovine primary aortic endothelial cells (BAEC), bovine primary mammary endothelial cells (BMEC), bovine immortalized mammary epithelial cells (MAC-T), and Madin-Darby bovine kidney cells (MDBK; $\mathrm{n}=3$ ). \#Presented value contains sample with cycle to threshold value $>35$ cycles. Values are presented as transcript abundance $\left(2^{-\Delta \mathrm{CT}}\right)$ relative to endogenous control gene $R P S 9$. 
CYP1A1. Relatively high lung expression of CYP1A1 may support the necessity of 19(R)-HETE production in the local pulmonary environment, where 20-HETE is potently vasoactive (Bièche et al., 2007; Fan et al., 2016). Robust hepatic CYP2C19 expression is unsurprising, given its role in xenobiotic metabolism; however, the greater hepatic expression relative to other xenobiotic-metabolizing CYP450 is not conserved in other species (Bièche et al., 2007; Hirota et al., 2013). Additionally, the extrahepatic expression of CYP2E1 and $C Y P 3 A 4$ was unexpected and novel, as previously published findings in cattle found little to no extrahepatic expression (Krüger et al., 2005; Darwish et al., 2010).

Interestingly, we found robust splenic expression of CYP2J2 compared with its expression in other tissues, as opposed to the relatively pronounced cardiac expression seen in other ruminants (Messina et al., 2010). In this regard, among CYP450 evaluated, CYP2J2 was the highest-expressing CYP450 in splenic tissue as well. This relatively greater splenic expression may be due to the preference of CYP2J2 for producing EET rather than linoleic acid-derived oxylipids or subterminal HETE. Because EET are a vasodilatory class of oxylipids, such increased expression relative to other tissues may facilitate at least partial control over splenic and hepatic blood flow (Fer et al., 2008; Di Pascoli et al., 2016).

When measuring oxylipids derived from the CYP450 enzymatic pathway, in addition to absolute values, it has proven beneficial to put outcomes in a context comparing the primary produced oxylipid to the metabolite formed from EPHX2. For example, in dairy cattle, the ratio of primary to secondary metabolites of the $\omega-6$ PUFA linoleic acid (epoxyoctadecenoic acid to dihydroxyoctadecenoic acid), is increased significantly in the milk and plasma of cows with coliform mastitis despite not all oxylipid concentrations significantly differing between sick and healthy animals (Mavangira et al., 2015). Differences in oxylipid abundance such as this have led others to focus on EPHX2 as a therapeutic target with clinically beneficial results, such as the amelioration of inflammation and pain from laminitis in horses (Guedes et al., 2017). Interestingly, despite its close-knit activity to CYP450 epoxygenases, EPHX2 expression was not distributed similarly to any epoxygenase enzyme. Nevertheless, EPHX2 had widespread expression throughout all tissues. As such, EPHX2 may indeed significantly contribute to oxylipid metabolism not only systemically but at the local level in tissues throughout the body.

Expression of epoxygenases in differing bovine in vitro cell types was overall less robust than expression in tissues, likely due to the cellular heterogeneity of tissues and known reduction of CYP450 expression soon after removal from parent tissues (Xiang et al., 2019). In general, no in vitro cell type expressed a profile of epoxygenases similar to the profile of any tissue. The low expression of CYP3A4 and CYP2E1 in cultured bovine cells, compared with the organ types from which they were originally derived, has indeed been noted previously (Talbot et al., 2016).

\section{$\omega$-Hydroxylases}

In addition to epoxide formation of mid-chain double bonds, CYP450 hydroxylate PUFA at the terminal carbon. Terminal carbon w-hydroxylases CYP4A11 and CYP4F2 produce the highly pro-inflammatory oxylipid 20-HETE from arachidonic acid (Johnson et al., 2015). Although not the only 2 enzymes to produce 20-HETE, CYP4F2 and CYP4A11 are the major contributors to 20-HETE production in other species (Lasker et al., 2000). Although the relative input of each CYP4 to 20-HETE production is unknown in cattle, these data suggest that on a transcription basis, CYP4A11 is the greater of the 2 , with production predominantly in the liver and kidney.

Aside from arachidonic acid, CYP4F2 has several substrates, including the oxylipid leukotriene B4 (LTB4) and vitamin E (Zhang et al., 2000; McDonald et al., 2009; Schmölz et al., 2016). Interestingly, despite reported widespread expression of $C Y P 4 F 2$ in cattle, this was the only CYP450 enzyme not found consistently in all tissues (Haga et al., 2015). Nonetheless, bovine CYP4 enzymes have proven to participate in mediating immune functions in organ microenvironments. Indeed, 20-HETE production in the mammary gland appears to be locally regulated (Mavangira et al., 2015; Kuhn et al., 2017). Cattle with lower expression of cutaneous CYP4F3, another CYP450 which metabolizes LTB4, also show resistance to ectoparasites by maintaining greater amounts of LTB4 (Tabor et al., 2017). Differential expression of CYP $4 F 2$ may also alter the rate of degradation of vitamin E. Certainly in other species, reduced expression of $C Y P 4 F 2$ slows the breakdown of vitamin $\mathrm{E}$; however, the contribution of $\mathrm{CYP} 4 \mathrm{~F} 2$ to circulating vitamin E concentrations in cattle is unknown (Bartolini et al., 2017). The lack of consistent expression of TCwH CYP4F2 and CYP4A11 cell culture models underscores why such research is so difficult to undertake. Although the CYP4 family of enzymes shows indications of important functions in organ microenvironments, a lack of cell culture models, as supported by these data, has prevented the study of such functions without transfection. 


\section{Vitamin D Metabolism}

Initial vitamin $\mathrm{D}$ from the diet or UV light exposure of the skin is metabolized to $25-(\mathrm{OH}) \mathrm{D}_{3}$ by several CYP450, including CYP2J2, CYP3A4, and CYP27A1, evaluated in this study. Of bovine 25 -hydroxylases, thus far only CYP2J2 and CYP27A1 have been associated with measurable contributions to calcium homeostasis. Such findings suggest that although other 25-hydroxylases may significantly produce $25-(\mathrm{OH}) \mathrm{D}_{3}$, at a minimum CYP2J2 and CYP27A1 play a role in vitamin D metabolism important enough to influence clinical disease (Casas et al., 2013; Pacheco et al., 2018). In other species, CYP2R1 appears to be the primary 25-hydroxylase, and in cattle, gene expression of $C Y P 2 R 1$ in mammary epithelial cells stimulated with cholecalciferol certainly increases in a dose-dependent manner, as would be expected with substrate supplementation (Téllez-Pérez et al., 2012; Christakos et al., 2016). Additionally, $C Y P 2 R 1$ has been associated with incidence of mastitis; however, it is unclear whether this is due to 25-hydroxylase activity or to a separate mechanism (Naderi et al., 2018). Despite these understandings, no direct evidence of the relative contribution of CYP2R1 to $25-(\mathrm{OH}) \mathrm{D}_{3}$ has been shown in cattle.

The importance of 25-hydroxylases in health is beginning to draw greater attention, as our understanding of how clinical and subclinical hypocalcemia influence the predisposition to other diseases improves. Given that hypocalcemia is implicated as a contributing factor to several periparturient cow disorders, the importance of 25-hydroxylases goes beyond milk fever alone (Rodríguez et al., 2017). The relatively high expression of CYP27A1 compared with other 25-hydroxylases bolsters the proposition by Pacheco et al. (2018) that it is indeed one of the primary drivers of $25-(\mathrm{OH}) \mathrm{D}_{3}$ production in cattle.

The active form of vitamin $\mathrm{D}_{3}, 1,25-(\mathrm{OH})_{2} \mathrm{D}_{3}$, is formed solely by CYP27B1 (Christakos et al., 2016). Previously thought to occur primarily in the kidney, these data and recent research in cattle show that expression is found widely throughout the body in many tissues and circulating leukocytes (Nelson et al., 2010a; Nelson et al., 2011). The activity of CYP27B1 outside of the kidney may be critical for the immune-modulating activities of $1,25-(\mathrm{OH})_{2} \mathrm{D}_{3}$. Specifically in the mammary gland, several studies have noted the antibacterial and anti-inflammatory properties of vitamin $\mathrm{D}$, as well as the importance of $C Y P{ }^{2} 7 B 1$ upregulation in response to pathogen insult (Merriman et al., 2017; Merriman et al., 2018). With relatively high expression in lung and uterine tissues, which commonly face pathogen challenge, CYP27B1 may contribute to the antibacterial defenses of these organs as well.
The final step in the vitamin D pathway is carried out by CYP24A1, which is generally induced by the metabolites it ultimately degrades to maintain appropriate 1,25- $(\mathrm{OH})_{2} \mathrm{D}_{3}$ amounts (Christakos et al., 2016). Its induction is inhibited by LPS, however, potentially acting as a defense mechanism against pathogen insult to prolong the activity of $1,25-(\mathrm{OH})_{2} \mathrm{D}_{3}$ (Nelson et al., 2010b).

\section{Vitamin A Degradation}

Three CYP450 of the CYP26 family of enzymes (CYP26A1, CYP26B1, CYP26C1) are primarily responsible for the degradation of the active forms of vitamin A, namely all-trans retinoic acid (AT-RA), 9-cis retinoic acid, and 13-cis retinoic acid. Of the 3 CYP26 enzymes, CYP26A1 was included in this profile due to its widespread tissue expression in humans, which was recapitulated in the current study despite previous research in cattle showing little extrahepatic expression (Krüger et al., 2005; Ross and Zolfaghari, 2011). Prominent expression in liver samples is conserved with other mammals, whereas robust expression in uterine tissue is not yet may represent a means for the tight regulation of vitamin A necessary during pregnancy in cattle (Topletz et al., 2012).

Similarly, CYP26A1 is also likely a key regulator in the role played by active forms of vitamin A in contributing to the inflammatory response to bacterial insult. Like CYP24A1, the induction of CYP26A1 is significantly reduced by LPS (Zolfaghari et al., 2007). Given the ability of AT-RA to protect bovine cells from oxidative stress and to potentiate the LPS-induced inflammatory cascade, preventing the induction of CYP26A1 may serve as a protective mechanism by prolonging the activity of AT-RA during infection (Shi et al., 2018; Xu et al., 2019).

\section{CONCLUSIONS}

This study provides evidence that CYP450 enzymes are widely transcriptionally expressed throughout all tissues of dairy cattle, although to varying amounts. Such widespread expression in distinct cell types aids in explaining how CYP450-derived oxylipids are differentially produced in localized compartments such as the mammary gland. Furthermore, profiling of commonly utilized in vitro cells revealed significantly lower overall CYP450 expression in cultured cells compared with isolated organ tissues. Nonetheless, these data provide a valuable foundation for future studies aiming to understand the metabolism of vitamins $\mathrm{A}, \mathrm{D}$, and $\mathrm{E}$ in cattle as well as the production of CYP450-derived oxylipids. 


\section{ACKNOWLEDGMENTS}

This work was funded in part by a grant (201767015-26676) from the Agriculture and Food Research Initiative Competitive Grants Programs of the USDA National Institute for Food and Agriculture (Washington, DC) and by an endowment from the Matilda R. Wilson Fund (Detroit, MI).

\section{REFERENCES}

Aguiar, M., R. Masse, and B. F. Gibbs. 2005. Regulation of cytochrome P450 by posttranslational modification. Drug Metab. Rev. 37:379-404.

Aherne, K. M., M. R. Davis, and L. M. Sordillo. 1995. Isolation and characterization of bovine mammary endothelial cells. Methods Cell Sci. 17:41-46.

Bartolini, D., P. Torquato, C. Barola, A. Russo, C. Rychlicki, D. Giusepponi, G. Bellezza, A. Sidoni, R. Galarini, G. Svegliati-Baroni, and F. Galli. 2017. Nonalcoholic fatty liver disease impairs the cytochrome P-450-dependent metabolism of alpha-tocopherol (vitamin E). J. Nutr. Biochem. 47:120-131.

Bièche, I., C. Narjoz, T. Asselah, S. Vacher, P. Marcellin, R. Lidereau, P. Beaune, and I. de Waziers. 2007. Reverse transcriptase-PCR quantification of mRNA levels from cytochrome (CYP)1, CYP2 and CYP3 families in 22 different human tissues. Pharmacogenet. Genomics 17:731-742.

Bylund, J., J. Ericsson, and E. H. Oliw. 1998. Analysis of cytochrome P450 metabolites of arachidonic and linoleic acids by liquid chromatography-mass spectrometry with ion trap MS. Anal. Biochem. 265:55-68.

Casas, E., R. J. Leach, T. A. Reinhardt, R. M. Thallman, J. D. Lippolis, G. L. Bennett, and L. A. Kuehn. 2013. A genomewide association study identified CYP2J2 as a gene controlling serum vitamin D status in beef cattle. J. Anim. Sci. 91:3549-3556.

Christakos, S., P. Dhawan, A. Verstuyf, L. Verlinden, and G. Carmeliet. 2016. Vitamin D: Metabolism, molecular mechanism of action, and pleiotropic effects. Physiol. Rev. 96:365-408.

Darwish, W. S., Y. Ikenaka, W. R. El-Ghareeb, and M. Ishizuka. 2010. High expression of the mRNA of cytochrome P450 and phase II enzymes in the lung and kidney tissues of cattle. Animal 4:20232029.

Di Pascoli, M., F. Zampieri, A. Verardo, P. Pesce, C. Turato, P. Angeli, D. Sacerdoti, and M. Bolognesi. 2016. Inhibition of epoxyeicosatrienoic acid production in rats with cirrhosis has beneficial effects on portal hypertension by reducing splanchnic vasodilation. Hepatology 64:923-930.

Fan, F., Y. Ge, W. Lv, M. R. Elliott, Y. Muroya, T. Hirata, G. W. Booz, and R. J. Roman. 2016. Molecular mechanisms and cell signaling of 20-hydroxyeicosatetraenoic acid in vascular pathophysiology. Front. Biosci. (Landmark Ed.) 21:1427-1463.

Fer, M., Y. Dreano, D. Lucas, L. Corcos, J. P. Salaun, F. Berthou, and Y. Amet. 2008. Metabolism of eicosapentaenoic and docosahexaenoic acids by recombinant human cytochromes P450. Arch. Biochem. Biophys. 471:116-125.

Gabbs, M., S. Leng, J. G. Devassy, M. Monirujjaman, and H. M. Aukema. 2015. Advances in our understanding of oxylipins derived from dietary PUFAs. Adv. Nutr. 6:513-540.

Guedes, A., L. Galuppo, D. Hood, S. H. Hwang, C. Morisseau, and B. D. Hammock. 2017. Soluble epoxide hydrolase activity and pharmacologic inhibition in horses with chronic severe laminitis. Equine Vet. J. 49:345-351.

Haga, S., M. Nakano, H. Ishizaki, S. G. Roh, and K. Katoh. 2015. Expression of alpha-tocopherol-associated genes and alpha-tocopherol accumulation in Japanese Black (Wagyu) calves with and without alpha-tocopherol supplementation. J. Anim. Sci. 93:4048-4057.
Hirota, T., S. Eguchi, and I. Ieiri. 2013. Impact of genetic polymorphisms in CYP2C9 and CYP2C19 on the pharmacokinetics of clinically used drugs. Drug Metab. Pharmacokinet. 28:28-37.

Holcombe, S. J., L. Wisnieski, J. Gandy, B. Norby, and L. M. Sordillo. 2018. Reduced serum vitamin D concentrations in healthy earlylactation dairy cattle. J. Dairy Sci. 101:1488-1494.

Huynh, H. T., G. Robitaille, and J. D. Turner. 1991. Establishment of bovine mammary epithelial cells (MAC-T): An in vitro model for bovine lactation. Exp. Cell Res. 197:191-199.

Johnson, A. L., K. Z. Edson, R. A. Totah, and A. E. Rettie. 2015. Cytochrome P450 omega-hydroxylases in inflammation and cancer. Adv. Pharmacol. 74:223-262.

Krüger, K. A., J. W. Blum, and D. L. Greger. 2005. Expression of nuclear receptor and target genes in liver and intestine of neonatal calves fed colostrum and vitamin A. J. Dairy Sci. 88:3971-3981.

Kuhn, M. J., V. Mavangira, J. C. Gandy, C. Zhang, A. D. Jones, and L. M. Sordillo. 2017. Differences in the oxylipid profiles of bovine milk and plasma at different stages of lactation. J. Agric. Food Chem. 65:4980-4988.

Lasker, J. M., W. B. Chen, I. Wolf, B. P. Bloswick, P. D. Wilson, and P. K. Powell. 2000. Formation of 20-hydroxyeicosatetraenoic acid, a vasoactive and natriuretic eicosanoid, in human kidney. Role of Cyp4F2 and Cyp4A11. J. Biol. Chem. 275:4118-4126.

LeBlanc, S. J., T. H. Herdt, W. M. Seymour, T. F. Duffield, and K. E. Leslie. 2004. Peripartum serum vitamin E, retinol, and beta-carotene in dairy cattle and their associations with disease. J. Dairy Sci. 87:609-619.

Lorenz, T. C. 2012. Polymerase chain reaction: Basic protocol plus troubleshooting and optimization strategies. J. Vis. Exp. e3998.

Madin, S. H., and N. B. Darby Jr.. 1958. Established kidney cell lines of normal adult bovine and ovine origin. Proc. Society for Experimental Biology and Medicine. Exp. Biol. Med. (Maywood) 98:574-576.

Mavangira, V., J. C. Gandy, C. Zhang, V. E. Ryman, A. Daniel Jones, and L. M. Sordillo. 2015. Polyunsaturated fatty acids influence differential biosynthesis of oxylipids and other lipid mediators during bovine coliform mastitis. J. Dairy Sci. 98:6202-6215.

McDonald, M. G., M. J. Rieder, M. Nakano, C. K. Hsia, and A. E. Rettie. 2009. CYP4F2 is a vitamin K1 oxidase: An explanation for altered warfarin dose in carriers of the V433M variant. Mol. Pharmacol. 75:1337-1346.

Merriman, K. E., M. B. Poindexter, M. F. Kweh, J. E. P. Santos, and C. D. Nelson. 2017. Intramammary 1,25-dihydroxyvitamin D3 treatment increases expression of host-defense genes in mammary immune cells of lactating dairy cattle. J. Steroid Biochem. Mol. Biol. 173:33-41.

Merriman, K. E., J. L. Powell, J. E. P. Santos, and C. D. Nelson. 2018. Intramammary 25-hydroxyvitamin D3 treatment modulates innate immune responses to endotoxin-induced mastitis. J. Dairy Sci. 101:7593-7607.

Messina, A., S. Nencioni, P. G. Gervasi, K. H. Gotlinger, M. L. Schwartzman, and V. Longo. 2010. Molecular cloning and enzymatic characterization of sheep CYP2J. Xenobiotica 40:109-118.

Naderi, S., M. Bohlouli, T. Yin, and S. Konig. 2018. Genomic breeding values, SNP effects and gene identification for disease traits in cow training sets. Anim. Genet. 49:178-192.

Nelson, C. D., B. J. Nonnecke, T. A. Reinhardt, W. R. Waters, D. C. Beitz, and J. D. Lippolis. 2011. Regulation of Mycobacterium-specific mononuclear cell responses by 25-hydroxyvitamin D3. PLoS One 6:e21674.

Nelson, C. D., T. A. Reinhardt, D. C. Beitz, and J. D. Lippolis. 2010a. In vivo activation of the intracrine vitamin $\mathrm{D}$ pathway in innate immune cells and mammary tissue during a bacterial infection. PLoS One 5:e15469.

Nelson, C. D., T. A. Reinhardt, T. C. Thacker, D. C. Beitz, and J. D. Lippolis. 2010b. Modulation of the bovine innate immune response by production of 1alpha,25-dihydroxyvitamin $\mathrm{D}(3)$ in bovine monocytes. J. Dairy Sci. 93:1041-1049.

Pacheco, H. A., S. da Silva, A. Sigdel, C. K. Mak, K. N. Galvao, R. A. Texeira, L. T. Dias, and F. Penagaricano. 2018. Gene mapping and 
gene-set analysis for milk fever incidence in Holstein dairy cattle. Front. Genet. 9:465.

Powell, P. K., I. Wolf, R. Jin, and J. M. Lasker. 1998. Metabolism of arachidonic acid to 20-hydroxy-5,8,11, 14-eicosatetraenoic acid by P450 enzymes in human liver: Involvement of CYP4F2 and CYP4A11. J. Pharmacol. Exp. Ther. 285:1327-1336.

Rodríguez, E. M., A. Arís, and A. Bach. 2017. Associations between subclinical hypocalcemia and postparturient diseases in dairy cows. J. Dairy Sci. 100:7427-7434.

Ross, A. C., and R. Zolfaghari. 2011. Cytochrome P450s in the regulation of cellular retinoic acid metabolism. Annu. Rev. Nutr. 31:6587.

Ryman, V. E., N. Packiriswamy, and L. M. Sordillo. 2016. Apoptosis of endothelial cells by 13-HPODE contributes to impairment of endothelial barrier integrity. Mediators Inflamm. 2016:9867138.

Schmölz, L., M. Birringer, S. Lorkowski, and M. Wallert. 2016. Complexity of vitamin E metabolism. World J. Biol. Chem. 7:14-43.

Shi, H. Y., S. M. Yan, Y. M. Guo, B. Q. Zhang, X. Y. Guo, and B. L. Shi. 2018. Vitamin A pretreatment protects NO-induced bovine mammary epithelial cells from oxidative stress by modulating Nrf2 and NF-kappaB signaling pathways. J. Anim. Sci. 96:1305-1316.

Sontag, T. J., and R. S. Parker. 2002. Cytochrome P450 omega-hydroxylase pathway of tocopherol catabolism. Novel mechanism of regulation of vitamin E status. J. Biol. Chem. 277:25290-25296.

Sordillo, L. M. 2016. Nutritional strategies to optimize dairy cattle immunity. J. Dairy Sci. 99:4967-4982.

Sordillo, L. M. 2018. Symposium review: Oxylipids and the regulation of bovine mammary inflammatory responses. J. Dairy Sci. 101:5629-5641.

Sordillo, L. M., and W. Raphael. 2013. Significance of metabolic stress, lipid mobilization, and inflammation on transition cow disorders. Vet. Clin. North Am. Food Anim. Pract. 29:267-278.

Tabor, A. E., A. Ali, G. Rehman, G. Rocha Garcia, A. F. Zangirolamo, T. Malardo, and N. N. Jonsson. 2017. Cattle tick Rhipicephalus microplus-host interface: A review of resistant and susceptible host responses. Front. Cell. Infect. Microbiol. 7:506.

Talbot, N. C., L. Wang, W. M. Garrett, T. J. Caperna, and Y. Tang. 2016. Establishment and characterization of feeder cell-dependent bovine fetal liver cell lines. In Vitro Cell. Dev. Biol. Anim. 52:314326.

Téllez-Pérez, A. D., N. Alva-Murillo, A. Ochoa-Zarzosa, and J. E. López-Meza. 2012. Cholecalciferol (vitamin D) differentially regu- lates antimicrobial peptide expression in bovine mammary epithelial cells: Implications during Staphylococcus aureus internalization. Vet. Microbiol. 160:91-98.

Topletz, A. R., J. E. Thatcher, A. Zelter, J. D. Lutz, S. Tay, W. L. Nelson, and N. Isoherranen. 2012. Comparison of the function and expression of CYP26A1 and CYP26B1, the two retinoic acid hydroxylases. Biochem. Pharmacol. 83:149-163.

Xiang, C., Y. Du, G. Meng, L. Soon Yi, S. Sun, N. Song, X. Zhang, Y. Xiao, J. Wang, Z. Yi, Y. Liu, B. Xie, M. Wu, J. Shu, D. Sun, J. Jia, Z. Liang, D. Sun, Y. Huang, Y. Shi, J. Xu, F. Lu, C. Li K. Xiang, Z. Yuan, S. Lu, and H. Deng. 2019. Long-term functional maintenance of primary human hepatocytes in vitro. Science 364:399-402.

Xu, Q., H. Jia, L. Ma, G. Liu, C. Xu, Y. Li, X. Li, and X. Li. 2019. All-trans retinoic acid inhibits lipopolysaccharide-induced inflammatory responses in bovine adipocytes via TGFbeta1/Smad3 signaling pathway. BMC Vet. Res. 15:48.

Yang, B., L. Graham, S. Dikalov, R. P. Mason, J. R. Falck, J. K. Liao, and D. C. Zeldin. 2001. Overexpression of cytochrome P450 CYP2J2 protects against hypoxia-reoxygenation injury in cultured bovine aortic endothelial cells. Mol. Pharmacol. 60:310-320.

Zhang, W. Y., H. Wang, S. Qi, X. Wang, X. Li, K. Zhou, Y. Zhang, and M. Q. Gao. 2018. CYP1A1 relieves lipopolysaccharide-induced inflammatory responses in bovine mammary epithelial cells. Mediators Inflamm. 2018:4093285.

Zhang, X., L. Chen, and J. P. Hardwick. 2000. Promoter activity and regulation of the CYP4F2 leukotriene $\mathrm{B}(4)$ omega-hydroxylase gene by peroxisomal proliferators and retinoic acid in HepG2 cells. Arch. Biochem. Biophys. 378:364-376.

Zolfaghari, R., C. J. Cifelli, S. O. Lieu, Q. Chen, N. Q. Li, and A. C. Ross. 2007. Lipopolysaccharide opposes the induction of CYP26A1 and CYP26B1 gene expression by retinoic acid in the rat liver in vivo. Am. J. Physiol. Gastrointest. Liver Physiol. 292:G1029 G1036.

\section{ORCIDS}

M. J. Kuhn ๑ https://orcid.org/0000-0002-0119-8325

A. K. Putman (1) https://orcid.org/0000-0002-5532-3427

L. M. Sordillo (i) https://orcid.org/0000-0001-8873-3134 